\title{
APLICAÇÃO DA FLUIDODINÂMICA COMPUTACIONAL (CFD) E ANÁLISE DE ACELERANTES NA INVESTIGAÇÃO DE INCÊNDIO
}

\author{
Igor O. P. da Cunha ${ }^{a, c}$, Wanderson Romão ${ }^{a, b,(1)}$ e Valdemar Lacerda Juniora,*,(1) \\ aDepartamento de Química, Universidade Federal do Espírito Santo, 29075-910 Vitória - ES, Brasil \\ 'Instituto Federal do Espírito Santo, 29106-010 Vila Velha - ES, Brasil \\ 'Departamento de Perícia de Incêndio e Explosão, Corpo de Bombeiros Militar do Estado do Espírito Santo, 29050-555 Vitória \\ - ES, Brasil
}

Recebido em 05/10/2019; aceito em 17/02/2020; publicado na web em 13/04/2020

\begin{abstract}
APPLICATION OF COMPUTER FLUID DYNAMICS (CFD) AND ANALYSIS OF ACCELERATORS IN FIRE INVESTIGATION.
Fire investigation is a complex activity that involves skill, technology, knowledge and science and aims to elucidate fire-related events such as cause, origin, propagation, phenomena, etc. Chemical analysis to verify the presence of foreign substances in that location, as well as the use of fire simulation software are efficient and economical ways to study fire behavior during the occurrence of fire. This work demonstrates the application of Gas Chromatography coupled to Mass Spectrometry (GC-MS) in the analysis for gasoline and diesel identification in different substrates, as well as the application of computational fluid dynamics (CFD) to aid in the elucidation of fires. The chemical analyses performed showed the possibility of identifying the presence of accelerants even in small quantities $(1 \mu \mathrm{L})$ and in different types of materials (wood, polyethylene, polyurethane, polyamide and newsprint). The computational model generated by the software proved to be consistent with the data obtained at the scene by the fire expert, thus serving in the hypothesis discard and conclusion of the investigation.
\end{abstract}

Keywords: investigation; fire; accelerating; simulation.

\section{INTRODUÇÃO}

O desenvolvimento da atividade de perícia ou investigação de incêndio e explosão está diretamente ligado à evolução do conhecimento relacionado à ciência do fogo. No Brasil, somente em 2017, a Segurança Contra Incêndio foi reconhecida como área do conhecimento pela CAPES e, em razão disso, pouco conhecimento foi produzido devido à falta de estudos nessa área. Somente no triênio 2016-2018, 14.097 atendimentos relacionados a incêndios foram realizados pelo Corpo de Bombeiros no âmbito do Estado do Espírito Santo, desse total, 539 foram objetos de investigação de incêndio. ${ }^{1}$

Diversos trabalhos são reportados aplicando software Fire Dynamics Simulator (FDS) para buscar entender os efeitos do incêndio e antecipar-se, caso viesse a ocorrer, incêndios em túnel, ${ }^{2-4}$ plataformas de exploração de petróleo, ${ }^{5}$ pontes, ${ }^{6}$ edifícios, ${ }^{7}$ entre outros. Na identificação de acelerantes destacam-se as aplicações quimiométricas, ${ }^{8}$ as otimizações realizadas por cromatografia gasosa acoplada a espectrometria de massas ${ }^{9}$ e análise direta por espectrometria de massas no espaço livre (E-Nose). ${ }^{10}$

Nesse escopo, surge a questão problema que deu origem a esse trabalho: quais aplicações práticas e limitações que as simulações computacionais de incêndio e análise química de acelerantes podem agregar de informações para a tomada de decisões do perito de incêndio?

Neste contexto, esse trabalho tem como objetivo descrever como essas práticas podem contribuir nos estudos investigativos da Perícia de Incêndio do Corpo de Bombeiros Militar do Espírito Santo. Para isso, foi realizada uma pesquisa de simulação computacional utilizando o software Fire Dynamics Simulator (FDS) em dois cenários reais de incêndio e uma análise química por cromatografia gasosa acoplada a espectrometria de massas (CG-EM) de diferentes tipos de

*e-mail: vljuniorqui@gmail.com materiais queimados (madeira, polietileno, poliuretano, poliamida e papel-jornal) com gasolina e diesel $(1 \mu \mathrm{L})$.

\section{Análise de acelerantes}

Quando um incêndio é iniciado deliberadamente, os incendiários usam líquidos inflamáveis que derramam sobre o local para ajudar dar início ao fogo, propagar e assim acelerar a destruição. ${ }^{11} \mathrm{Um}$ acelerante é qualquer combustível ou oxidante, muitas vezes um líquido inflamável, usado para iniciar um incêndio, aumentar a taxa de crescimento e acelerar a propagação do fogo. ${ }^{12}$

Os acelerantes podem ser encontrados em qualquer estado físico: gás, líquido ou sólido. As provas para testes de aceleração devem ser coletadas e testadas de acordo com as normas da American Society for Testing and Materials (ASTM), ${ }^{12}$ uma vez que a detecção de resíduos acelerados afeta de forma decisiva o curso de investigação de incêndio e constitui importantes evidências materiais do crime, a confiabilidade desses testes é de extrema importância. ${ }^{13}$

A gasolina é o combustível mais comumente utilizado como acelerante, porque é um líquido inflamável eficiente e pode ser comprado e transportado mesmo em grandes quantidades sem despertar as suspeitas dos vendedores e das autoridades, assim como os diluentes de tinta e o querosene que são combustíveis bastantes comuns e podem ser adquiridos em quantidades moderadas sem a suspeita, pois seu uso é liberado com pouca restrição. ${ }^{14}$

Durante as investigações se for determinado que um incêndio seja de causa criminosa ou de forma ilegal na propriedade, uma investigação criminal completa deve ser conduzida. Outros incêndios para os quais uma causa não pode ser facilmente determinada, incluindo aqueles classificados como suspeitos ou indeterminados, também devem ser investigados. ${ }^{15}$

Muitos incêndios criminosos estão associados à utilização de acelerantes, sendo que a presença de um acelerador numa cena de incêndio pode indicar que um ato de incêndio ocorreu em oposição 
a um incêndio acidental. Um acelerador pode ser qualquer material usado para facilitar a ignição ou contribuir para a velocidade ou a propagação de um incêndio. O incêndio criminoso é considerado um dos crimes mais fáceis de cometer e uma das mais difíceis de investigar. $^{16}$

\section{Cromatografia gasosa acoplada a espectrometria de massas (CG-EM)}

A cromatografia abrange uma série de técnicas que têm em comum a separação dos componentes de uma mistura por operações de equilíbrio que resultam na separação das espécies como resultado de sua partição (sorção diferencial) entre duas fases diferentes, uma estacionária com uma superfície grande e uma em movimento em contato com a primeira. A cromatografia não se restringe a separações analíticas podendo também ser usada na preparação de substâncias puras, no estudo da cinética das reações, nas investigações estruturais de escala molecular e na determinação de constantes físico-químicas, incluindo constantes de estabilidade de complexos, entalpia, entropia e energia livre. ${ }^{17}$

Em uma revisão realizada por Martín-Alberca et al. $(2016)^{18}$ sobre as ferramentas de análise utilizadas para detectar a presença de acelerantes em detritos de incêndio durante os anos de 2008-2015, os autores trouxeram que é uma área amplamente dominada pela técnica de CG acoplada a um detector EM, apresentando apenas algumas limitações para separar e identificar isômeros estruturais e hidrocarbonetos pesados de misturas complexas.

Para a preparação da amostra para ser analisada por CG-EM é necessário seguir algumas metodologias próprias para esse tipo de material, com destaque para a ASTM E1412 que normatiza a utilização do extração por carvão ativado (ACS) para separação e concentração de resíduos líquidos inflamáveis de amostras de detritos de fogo, considerada ser uma técnica adequada para a detecção dos resíduos de líquidos inflamáveis (ILRs), para avaliar a sua concentração e para extrai-los das amostras. ${ }^{19}$

A técnica consiste em expor o carvão vegetal no recipiente da amostra para adsorver resíduos líquidos inflamáveis, sendo que o recipiente pode ser aquecido ou deixado à temperatura ambiente por um determinado tempo. Em seguida o carvão é removido e eluído com dissulfureto de carbono (CS2), diclorometano (DCM) ou éter dietílico e analisado utilizando alguma técnica analítica, comumente sendo empregada a CG-EM. ${ }^{19}$

Diversos estudos utilizam o ACS para extração dos ILRs, com destaque para os trabalhos realizados por Salgueiro et al. (2012) que utilizaram o ACS a uma temperatura de $80 \pm 1{ }^{\circ} \mathrm{C}$ por $14,0 \pm 0,5 \mathrm{~h}$ no forno para extrair e identificar gasolina de 95 octanas, gasolina de 98 octanas, diluente de tinta, iniciador de carvão sólido e aguarrás. ${ }^{20} \mathrm{No}$ mesmo ano, Prather et al. (2012) também utilizou a ACS (de 2,5 mm por $5 \mathrm{~mm}$, da marca Albrayco Laboratories) em seus trabalhos, otimizando a extração utilizando uma temperatura de $80^{\circ} \mathrm{C}$ durante $4 \mathrm{~h}$. Decorrido esse tempo, a tira de carbono foi eluída com $200 \mathrm{~mL}$ de diclorometano obtendo-se excelentes resultados na análise para detectar gasolina e querosene. ${ }^{21}$

Lopatka et al. (2015) $)^{22}$ utilizaram a ACS (também da marca Albrayco Technologies) e otimizaram a análise para a detecção de gasolina usando uma temperatura de $66^{\circ} \mathrm{C}$, um tempo de extração de 16 horas e o dissulfureto de carbono para eluir o carvão ativado. No ano seguinte, no trabalho de Sandercock (2016) ${ }^{23}$ avaliou-se a utilização de um pano de carbono ativado (ACC) e uma tira de carbono ativado (ACS) na extração de vários líquidos inflamáveis. As extrações simultâneas de líquidos inflamáveis utilizando ACC e ACS foram realizadas durante um período de 16 horas em latas de tinta de um litro, tanto a temperatura ambiente quanto a $60{ }^{\circ} \mathrm{C}$.
As extrações aquecidas também foram realizadas em uma mistura aceleradora de gasolina e diesel na presença de vapor de água e o efeito do vapor de água sobre a eficiência de extração de ACC e ACS foi avaliado.

\section{Fire Dynamics Simulator (FDS)}

O FDS é um software de dinâmica computacional de fluidos (CFD) que calcula o fluxo de calor impulsionado pelo fogo e é disponibilizado gratuitamente pelo National Institute of Standards and Technology (NIST). O software resolve numericamente uma forma das equações de Navier-Stokes apropriado para a baixa velocidade, fluxo térmico com ênfase na fumaça e no transporte de calor dos incêndios. $^{24}$

Ele resolve numericamente uma forma das equações de NavierStokes apropriadas para fluxo de baixa velocidade com ênfase no transporte de fumaça e calor dos incêndios. A turbulência é tratada de maneira padrão por meio da simulação de grandes redemoinhos (LES), no entanto, o modelo adotado pode ser alterado para simulação numérica de direção (DNS), simulação de redemoinhos muito grandes (VLES) e simulação de redemoinhos muito grandes simples (SVLES). A combustão é baseada na mistura de reação limitada, infinitamente rápida de espécies que se aglomeram e reagem em escalas que representam a misturas dessas espécies. A radiação térmica é calculada resolvendo a equação de transporte de radiação para o gás cinza utilizando o método do volume finito (MVF). ${ }^{24}$

A primeira versão do FDS foi lançada publicamente em fevereiro do ano 2000, sendo usado para criar um modelo de transporte de calor, predizer produtos da combustão em baixas velocidades, transferência de calor por radiação e convecção entre gases e superfícies sólidas, pirólise dos materiais sólidos, como ocorre a propagação das chamas e o crescimento do incêndio, capaz também de testar a ativação de chuveiros automáticos, detectores de temperatura, fumaça e supressão de incêndios com água por aspersão com chuveiros automáticos. ${ }^{24}$

Todos os parâmetros de entrada requeridos pelo FDS para descrever um cenário de incêndio são transmitidos por meio de um arquivo de texto criado pelo usuário, baseado em comandos específicos de acordo com o guia de usuário disponível no site. Neste arquivo de entrada devem constar informações acerca do domínio físico e computacional, a geometria do ambiente e dos objetos, as propriedades físico-químicas dos materiais, bem como especificações sobre a reação de combustão e dados de saída a serem gravados. ${ }^{25}$

Em uma busca realizada no site www.periodicoscapes.gov.br utilizando-se o termo "Fire Dynamics Simulator", observa-se um total de 1.178 publicações de periódicos revisados por pares desde o lançamento do software em 2000, sendo que 58,91\% dessas publicações estão concentradas nos últimos 5 anos. ${ }^{26}$ A Figura 1 apresenta a distribuição desses artigos em função do tempo.

Diversos estudos com aplicação do FDS na elucidação das causas do incêndio foram realizados, com destaque para os estudos desenvolvidos pelo NIST, entre eles: simulação da dinâmica do incêndio para o caso do World Trade Center (WTC) em 11 de setembro de $2001,{ }^{28}$ após o atentado terrorista; o incêndio na boate Station em Rhode Island em fevereiro de 2003, ${ }^{29}$ simulação da dinâmica do fogo na Cherry Road NE em Washington D.C., ocorrido em 30 de maio de $1999 ;{ }^{30}$ simulação da dinâmica de um incêndio em um duplex em Iowa, ocorrido em 22 de dezembro de $1999 ;{ }^{31}$ simulação da dinâmica de um incêndio no porão de uma loja de ferragens, Nova York, ocorrido em 17 de junho de $2001^{32}$ e a simulação da dinâmica de um fogo movido pelo vento em uma casa de estilo rural, Texas, ocorrido em 2009.33 


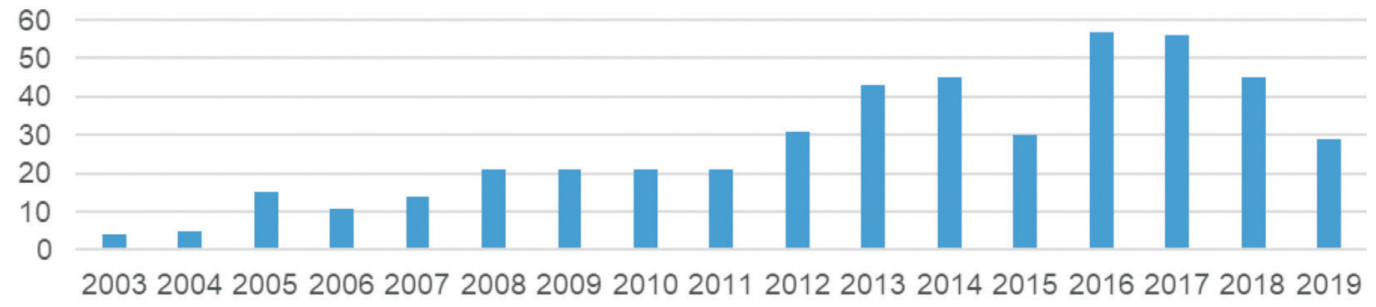

Figura 1. Evolução do quantitativo de publicações com aplicações do software FDS ${ }^{27}$

\section{PARTE EXPERIMENTAL}

\section{Análise de acelerantes}

Os substratos utilizados foram: madeira (eucalipto), plástico (polietileno), espuma (poliuretano), tecido (poliamida) e papel-jornal (celulose). Todos os substratos foram depositados em três pedaços no interior de blocos de dimensões média de $10 \times 10 \mathrm{~cm}^{2}$. Os acelerantes foram depositados em uma quantidade de $1 \mu \mathrm{L}$ sobre cada pedaço do substrato, sendo eles: gasolina e diesel.

A ignição do substrato com o acelerante foi feita utilizando um isqueiro e a extinção das chamas foi realizada, após 30 segundos do início da ignição, utilizando o princípio do abafamento. Na extinção por abafamento, uma placa de madeira foi utilizada para bloquear a passagem do oxigênio atmosférico para a amostra. Posteriormente, a amostra sólida foi coletada para o interior de um recipiente metálico, onde um pedaço da fibra de carvão foi colocado sobre o espaço vazio do recipiente, sem contato direto com a amostra.

Para a extração dos elementos de interesse, foi utilizada uma fibra de carvão ativado empregada em exaustores de ar para filtragem de gases nocivos, que foi extraído durante um tempo de 12 horas em uma estufa de $120^{\circ} \mathrm{C}$, e posteriormente dessorvido utilizando $2 \mathrm{~mL}$ de diclorometano (DCM).

A análise dos produtos de combustão foi realizada em um cromatógrafo a gás modelo Agilent $6890 \mathrm{~N}$ com uma coluna HP-5ms com 30 metros de comprimento, diâmetro interno: $0,25 \mathrm{~mm}$, e gás portador: hélio (pureza ultraelevada). Os parâmetros de análise foram: vazão constante de $0,80 \mathrm{~mL} \mathrm{~min}{ }^{-1}$, volume de injeção: $1 \mathrm{~mL}$, temperatura de injeção: $40^{\circ} \mathrm{C}$, tempo de espera inicial: $3 \mathrm{~min}$, taxa de aquecimento de $5{ }^{\circ} \mathrm{C} \mathrm{min}-1$ até $150{ }^{\circ} \mathrm{C} \mathrm{e} 15^{\circ} \mathrm{C} \mathrm{min}^{-1}$ até $300{ }^{\circ} \mathrm{C}$, tempo final de espera: $1 \mathrm{~min}$, e tempo total de execução: $36 \mathrm{~min}$.

\section{Fluidodinâmica computacional (CFD)}

O software utilizado para realização da simulação foi o Fire Dynamics Simulator (FDS). Toda simulação foi montada com base nas informações repassadas pelo perito responsável pelo local da perícia em seu laudo investigativo e por visita in loco, para verificar o tipo de material existente no local. Nenhum dos dois casos estudados foi identificado, restringindo-se assim a análise do desenvolvimento do incêndio, preservando as pessoas diretamente envolvidas. As propriedades térmicas dos materiais foram obtidas com base no banco de dados de itens queimados criado pelo Centro Nacional de Ciência Forense (NCFS) da Universidade da Flórida Central (UCF) em parceria com o Departamento de Engenharia de Proteção contra Incêndios da Universidade de Maryland College Park (UMCP).

Para a execução da simulação foi utilizada um Desktop HP EliteOne 800, processador Core i5-4590S, 8GB RAM e HD 500GB.

\section{Estudo de caso $n^{\circ} 1$}

Trata-se de um incêndio ocorrido no Estado do Espírito Santo no ano de 2018 que resultou na morte de duas pessoas. O caso em si não será aprofundado para preservar o nome das vítimas e envolvidos, limitando-se aos resultados obtidos pela análise computacional, comparando com os danos encontrados no cenário do incêndio. A simulação ocorreu em um tempo de 10 minutos, tendo em vista que se buscava entender as condições alcançadas no interior de um quarto, conforme croqui apresentado na Figura 2, e confrontar com as condições encontradas pela guarnição do Corpo de Bombeiros. O tempo de 10 minutos foi definido com base na linha do tempo construída utilizando-se as imagens de uma câmera de vídeo-monitoramente existente na região, onde entre o tempo que foi possível visualizar a saída da fumaça, até a chegada do caminhão dos bombeiros para realizar o combate ao incêndio, decorreu-se um tempo de 8 minutos.

A geometria da estrutura, aberturas de portas e janelas para o exterior, que influenciam criticamente o crescimento e a propagação do fogo, foram feitas com base na planta baixa da edificação, o tamanho da malha computacional foi de $10 \mathrm{~cm}$, a localização da fonte de ignição foi feita levando em conta a hipótese formulada pelo perito, a liberação de energia da fonte de ignição foi feita distribuindo a energia liberada na queima de um televisor de 28 polegadas, propriedades térmicas de paredes, teto, pisos e móveis, e o tamanho, localização foram feitos com base no banco de dados da NCFS. Toda parametrização utilizada foi baseada em estudos realizados e validados para comparar a eficiência do software com incêndios ocorridos em escala real.

Para simular a queima do ar condicionado, foram utilizados os parâmetros de queima de um televisor de 28 polegadas por apresentarem formato, massa e constituição similar. Conforme banco de dados do Centro Nacional de Ciência Forense (NCFS) da Universidade da Flórida Central (UCF), a queima ocorrerá conforme as condições apresentadas na Tabela 1S. A base dos materiais presentes no quarto foi simplificada em 3 materiais constituintes, sendo eles: madeira, espuma de poliuretano e tecido, sendo apresentadas as especificações na Tabela 2S.

As condições atingidas durante o incêndio foram monitoradas a partir de 6 dispositivos que foram instalados para monitorar a temperatura e o fluxo de calor. Com os dados obtidos, foi possível obter um perfil de temperatura, fluxo de calor do ambiente e avaliar as condições que foram alcançadas com o desenvolvimento do incêndio.

\section{Estudo de caso $n^{\circ} 2$}

Nesse estudo de caso, busca-se simular outro incêndio ocorrido no Estado do Espírito Santo no ano de 2018 que vitimou uma criança na capital do Estado. A simulação ocorreu durante um tempo de 1800 segundos (30 minutos) para tentar entender as condições alcançadas no interior da edificação, durante o desenvolvimento do incêndio e um possível cenário descrito pelo perito foi executado com as seguintes características: portas e janelas abertas, com exceção da porta de acesso ao banheiro, que permaneceu fechada após o início do incêndio, dimensões da cama e do sofá verificadas no local do ocorrido.

As parametrizações desses materiais foram obtidas com base em bibliografias que validaram esse tipo de material, utilizando-se de forma análoga as utilizadas no Estudo de caso $n^{\circ} 1$. Como carga de incêndio na edificação, foram consideradas apenas: uma cama de 


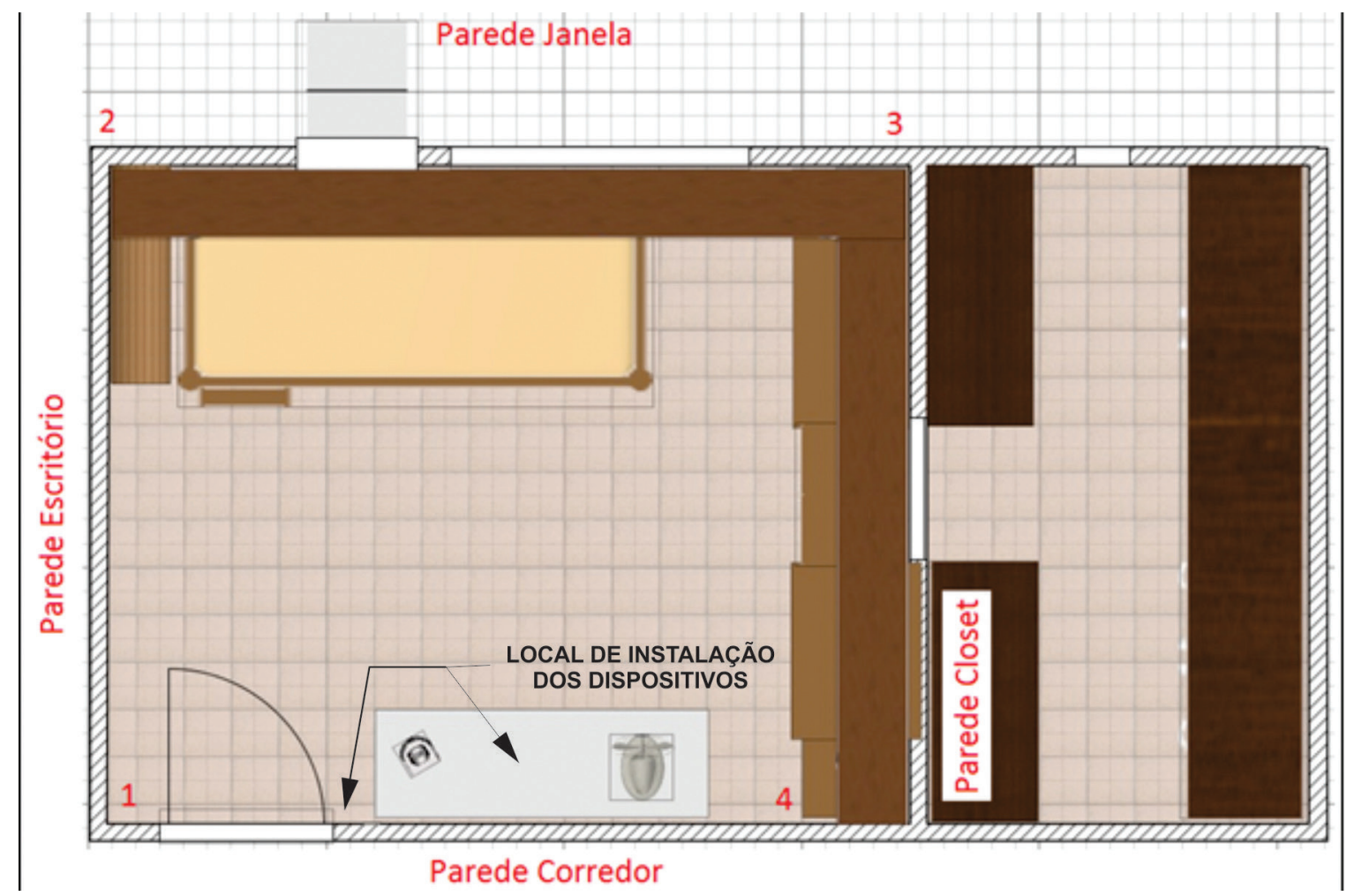

Figura 2. Planta baixa do quarto onde ocorreu o incêndio

casal do tipo box, dois colchões de casal, um cabideiro com roupas e a porta que liga o quarto ao banheiro, conforme apresentado no croqui da Figura 3. Dessa forma, o ambiente computacional simulado foi simplificado em comparação ao local do incêndio, por considerar que os colchões queimados são a principal fonte de energia liberada no incêndio, dessa forma com a maior parcela de contribuição para o incêndio ocorrido.

Para monitorar as condições atingidas durante o incêndio, foram colocados 35 dispositivos para medir a temperatura, fluxo de calor e visibilidade no ambiente investigado. Desses dispositivos, 15 foram posicionados na entrada da casa, nas alturas de $0,4 \mathrm{~m} ; 0,8 \mathrm{~m} ; 1,2 \mathrm{~m}$; $1,6 \mathrm{~m}$ e $2,0 \mathrm{~m}, 15$ dispositivos na região do quarto, nas mesmas alturas, próximo a porta de entrada do ambiente, 3 no interior do banheiro em uma altura de 0,4 m, 1 na porta do banheiro e 1 no sofá para monitorar a temperatura do objeto. Com os dados obtidos, foi possível obter um perfil de temperatura, fluxo de calor e visibilidade do ambiente e com isso avaliar as condições que foram alcançadas com o desenvolvimento do incêndio.

\section{RESULTADOS E DISCUSSÃO}

\section{Análise de acelerantes}

Os principais compostos químicos identificados nos cromatogramas da Figura 39S foram numerados e sua identidade revelada na Tabela 1. A gasolina e o diesel são frações do petróleo, o primeiro contendo de 4 a 12 átomos de carbono em estrutura molecular que enquadram em três tipos gerais: parafinas (incluindo cicloparafinas e materiais ramificados), olefinas e aromáticos, sendo sua distribuição básica composta por alcanos (4 a 8\%), alcenos (2 a 5\%), isoalcanos ( 25 a 40\%), cicloalcanos (3 a 7\%), cicloalcenos (1 a 4\%) e aromáticos (20-50\%), enquanto que o segundo contém, predominantemente, mais de nove átomos de carbonos em sua constituição, constituído por hidrocarbonetos parafínicos, olefínicos e aromáticos. O óleo diesel é formulado através da mistura de diversas correntes como gasóleos, nafta pesada, diesel leve e diesel pesado, provenientes das diversas etapas de processamento do petróleo bruto. ${ }^{34}$

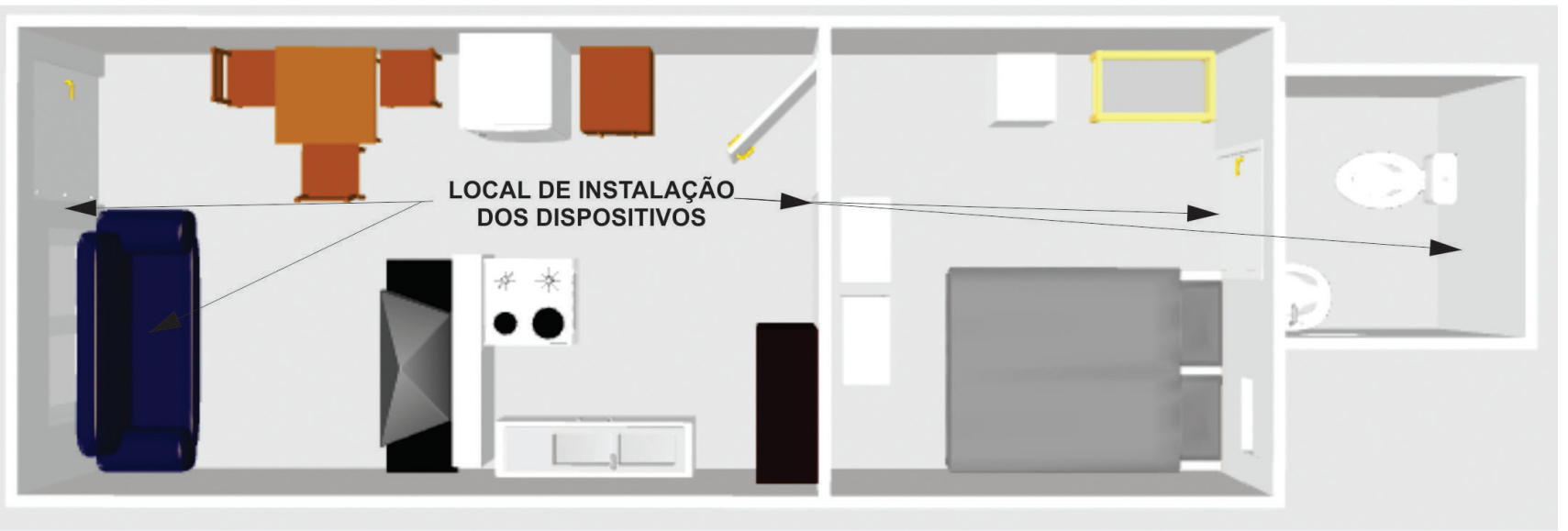

Figura 3. Planta baixa da edificação onde ocorreu o incêndio 
Tabela 1. Compostos químicos identificados como marcadores dos acelerantes de gasolina (1-8) e diesel (6, 9-14)

\begin{tabular}{|c|c|c|c|c|c|c|c|c|}
\hline Rótulo & Combustível & Composto & $\mathrm{T}_{\mathrm{R}}(\mathrm{min})$ & Tecido & Papel & Plástico & Madeira & Espuma \\
\hline 1 & \multirow{8}{*}{ Gasolina } & Tolueno & 7,0731 & - & - & - & $\mathrm{X}$ & $\mathrm{X}$ \\
\hline 2 & & $\alpha$-Xileno & 10,0194 & $\mathrm{X}$ & $\mathrm{X}$ & - & $\mathrm{X}$ & $\mathrm{X}$ \\
\hline 3 & & 1-etil-2-metil-benzeno & 12,9949 & $\mathrm{X}$ & $\mathrm{X}$ & $\mathrm{X}$ & $\mathrm{X}$ & $\mathrm{X}$ \\
\hline 4 & & 1,3,5-trimetil-benzeno & 14,0609 & $\mathrm{X}$ & $\mathrm{X}$ & $\mathrm{X}$ & $\mathrm{X}$ & $\mathrm{X}$ \\
\hline 5 & & 1h-indene, 1,2,3-dihidro-5-metil & 16,7543 & $\mathrm{X}$ & $\mathrm{X}$ & $\mathrm{X}$ & $\mathrm{X}$ & $\mathrm{X}$ \\
\hline 6 & & Dodecano & $18,9332 / 20,2296^{*}$ & $\mathrm{X}$ & $\mathrm{X}$ & $\mathrm{X}$ & $\mathrm{X}$ & $\mathrm{X}$ \\
\hline 7 & & Penta-metil-benzeno & 20,2830 & $\mathrm{X}$ & $\mathrm{X}$ & $\mathrm{X}$ & $\mathrm{X}$ & $\mathrm{X}$ \\
\hline 8 & & 1h-indene, 2,3-dihidro-4,7-dimetil & 21,6522 & $\mathrm{X}$ & - & $\mathrm{X}$ & $\mathrm{X}$ & $\mathrm{X}$ \\
\hline 9 & \multirow{6}{*}{ Diesel } & Tridecano & 23,0214 & $\mathrm{X}$ & $\mathrm{X}$ & $\mathrm{X}$ & $\mathrm{X}$ & $\mathrm{X}$ \\
\hline 10 & & Tetradecano & 25,5865 & $\mathrm{X}$ & $\mathrm{X}$ & $\mathrm{X}$ & $\mathrm{X}$ & $\mathrm{X}$ \\
\hline 11 & & Pentadecano & 27,4010 & $X$ & $X$ & $\mathrm{X}$ & $X$ & $\mathrm{X}$ \\
\hline 12 & & Hexadecano & 28,7239 & $\mathrm{X}$ & $\mathrm{X}$ & $\mathrm{X}$ & $\mathrm{X}$ & $\mathrm{X}$ \\
\hline 13 & & Heptadecano & 29,8529 & $X$ & $\mathrm{X}$ & $X$ & $\mathrm{X}$ & $\mathrm{X}$ \\
\hline 14 & & Eicosane & 32,1898 & $\mathrm{X}$ & $\mathrm{X}$ & $\mathrm{X}$ & $\mathrm{X}$ & $\mathrm{X}$ \\
\hline
\end{tabular}

*Hidrocarboneto utilizado como marcador na gasolina $\left(T_{R}=18,9332 \mathrm{~min}\right)$ e no diesel $\left(T_{R}=20,2296 \mathrm{~min}\right)$.

No material suplementar foram apresentados os resultados das análises por CG-EM dos substratos espuma, tecido, papel jornal, plástico e madeira, respectivamente, que foram queimados de forma natural, com gasolina e com diesel (Figuras 39S-41S).

De uma maneira geral, quando comparamos à capacidade do acelerante em ser identificado, o diesel demonstrou ser melhor do que a gasolina, onde nos substratos com menor capacidade de absorção, como o plástico, jornal e o tecido sintético, sinais correspondendo a marcadores químicos do diesel (dodecano, tridecano, pentadecano, hexadecano, heptadecano e eicosano) foram facilmente identificados, sendo que os marcadores químicos da gasolina (tolueno, $\alpha$-xileno, 1-etil-2-metil-benzeno, 1,3,5-trimetil-benzeno, 1h-indene, 1,2,3-dihidro-5-metil, dodecano, penta-metil-benzeno, 1h-indene, 1,2,3-dihidro-5-metil) apresentaram uma menor abundância. ${ }^{35}$ Isso se deve ao fato do diesel ser formado por hidrocarbonetos com maior massa molar do que o da gasolina, e dessa forma, apresentando uma temperatura de vaporização de seus componentes na faixa de 288 a $338{ }^{\circ} \mathrm{C},{ }^{36}$ o que dificulta a sua perda durante a queima do substrato. Por outro lado, a gasolina, apresenta uma temperatura de vaporização de seus componentes na faixa de 14 a $135^{\circ} \mathrm{C} .{ }^{37}$

Entre os materiais estudados como substrato, percebe-se que a espuma teve a melhor capacidade de conservação dos combustíveis quando comparado aos outros substratos e mesmo após 12 horas da queima, realizada com diesel, foi possível identificar os compostos químicos marcadores do combustível. Esse comportamento pode ser explicado pelo fato desse material (espuma de poliuretana) apresentar uma menor densidade $\left(0,02 \mathrm{~g} \mathrm{~cm}^{-3}\right)$ em relação aos demais (madeira: $0,49 \mathrm{~g} \mathrm{~cm}^{-3}$; polietileno: $1,35 \mathrm{~g} \mathrm{~cm}^{-3}$; papel-jornal: $0,93 \mathrm{~g} \mathrm{~cm}^{-3}$; poliamida: $\left.1,13 \mathrm{~g} \mathrm{~cm}^{-3}\right) \cdot{ }^{38}$ Como consequência dessa propriedade, sua elevada porosidade confere a espuma de PU uma alta capacidade de absorção de líquidos, fazendo com que a substância fique retida em seu interior, o que acaba inibindo-a da combustão durante um período maior. ${ }^{38}$ Por outro lado, o polietileno demonstrou ter uma pior capacidade de conservação de combustível, devido ao fato de suas características de impermeabilidade, limitando o acelerante a permanecer em sua superfície. Além disso, o elevado potencial calorífico do plástico (44 $\mathrm{MJ} \mathrm{kg}^{-1}$ ), comparado aos outros materiais (madeira: $19 \mathrm{MJ} \mathrm{kg}^{-1}$, papel-jornal: $17 \mathrm{MJ} \mathrm{kg}^{-1}$, poliuretano: $23 \mathrm{MJ} \mathrm{kg}^{-1}$, e poliamida: $\left.32 \mathrm{MJ} \mathrm{kg}^{-1}\right)^{39}$ faz com que a reação de combustão se desenvolva de maneira mais rápida, levando ao consumo do acelerante e dificultando sua posterior identificação.

A Tabela 2 apresenta a porcentagem de similaridade para cada composto-alvo identificado na queima dos substratos com o acelerante, onde em todos os casos o valor foi superior a $80 \%$. Entre os substratos utilizados, é possível perceber que a similaridade dos compostos-alvo foram maiores na espuma ( $>89 \%$ ), devido a maior abundância desses componentes, o que facilita assim, uma maior área cromatográfica detectada para cada composto e como consequência uma melhor qualidade no espectro de CG-EM produzido.

Analisando a literatura, não foram encontrados trabalhos avaliando a capacidade de absorção e a taxa de evaporação de combustível nesses substratos, limitando-se a estudar a interferência causada pela queima do substrato na identificação do agente acelerante. Destacamos o trabalho de Stauffer e Byron ${ }^{40}$ que, em 2008, perceberam que os detergentes de lavar louça, por vezes utilizados como alternativa de espumas comerciais pelo pessoal que trabalha com a atividade de combate a incêndios, apresentam em sua composição química moléculas de tolueno, etilbenzeno, xilenos, indano, naftaleno e naftalenos mono-substituído e padrões de alquilbenzenos lineares semelhantes ao padrão de alcanos em um destilado de petróleo. Esses compostos são portanto moléculas marcadores para a detecção de líquidos inflamáveis.

Já em 2015, nos trabalhos desenvolvidos por Visotin e Lennard, ${ }^{41}$ a gasolina foi corretamente identificada nas amostras de detritos de incêndio em tapetes de lã, telhas cerâmicas e queima de assoalho de madeira. Entretanto, para a amostra de tapete sintético, existiu uma interferência dos produtos de pirólise. Entre eles, o estireno era o composto mais abundante dentro do cromatograma.

Em relação à capacidade do fundo em interferir na identificação dos acelerantes, observa-se que em todos os substratos foi possível realizar a identificação do acelerante. No entanto, a queima do substrato do tipo tecido e madeira, apresentou uma elevada quantidade de outras substâncias observadas no cromatograma, como ácido 2-propanoico butil ester $\left(t_{R}=10,84 \mathrm{~min}\right)$ e fenol, 2,4-bis 1,1-dimetiletil $\left(\mathrm{t}_{\mathrm{R}}=27,54 \mathrm{~min}\right)$, o que pode prejudicar a identificação caso o tempo de coleta do substrato com o acelerante seja mais elevado, diminuindo assim, a quantidade de combustível recuperado no processo de extração.

\section{Fire Dynamics Simulator (FDS)}

\section{Estudo de caso $n^{\circ} 1$}

Foram feitos alguns apontamentos baseados nos efeitos da temperatura e fluxo de calor observado pelo incêndio que evoluiu partindo da região do ar condicionado e se espalhando pelo colchão da cama superior, que foi a hipótese testada para a ocorrência do 
Tabela 2. Porcentagem de similaridade de cada composto-alvo identificado nos substratos

\begin{tabular}{|c|c|c|c|c|}
\hline Substrato & Compostos-alvo (Gasolina) & Similaridade $(\%)$ & Compostos-alvo (Diesel) & Similaridade $(\%)$ \\
\hline \multirow{7}{*}{ Tecido } & $\alpha$-Xileno & 80 & Dodecano & 97 \\
\hline & 1-etil-2-metil-benzeno & 82 & Tridecano & 98 \\
\hline & 1,3,5-trimetil-benzeno & 83 & Tetradecano & 95 \\
\hline & 1h-indene, 1,2,3-dihidro-5-metil & 82 & Pentadecano & 89 \\
\hline & Dodecano & 95 & Hexadecano & 82 \\
\hline & Penta-metil-benzeno & 81 & Heptadecano & 83 \\
\hline & 1h-indene, 2,3-dihidro-4,7-dimetil & 89 & Eicosane & 82 \\
\hline \multirow{7}{*}{ Papel } & $\alpha$-Xileno & 93 & Dodecano & 93 \\
\hline & 1-etil-2-metil-benzeno & 97 & Tridecano & 97 \\
\hline & 1,3,5-trimetil-benzeno & 80 & Tetradecano & 98 \\
\hline & 1h-indene, 1,2,3-dihidro-5-metil & 82 & Pentadecano & 95 \\
\hline & Dodecano & 83 & Hexadecano & 99 \\
\hline & Penta-metil-benzeno & 82 & Heptadecano & 95 \\
\hline & - & 81 & Eicosane & 81 \\
\hline \multirow{7}{*}{ Plástico } & 1-etil-2-metil-benzeno & 89 & Dodecano & 89 \\
\hline & 1,3,5-trimetil-benzeno & 93 & Tridecano & 93 \\
\hline & 1h-indene, 1,2,3-dihidro-5-metil & 85 & Tetradecano & 87 \\
\hline & Dodecano & 80 & Pentadecano & 82 \\
\hline & Penta-metil-benzeno & 82 & Hexadecano & 83 \\
\hline & 1h-indene, 2,3-dihidro-4,7-dimetil & 83 & Heptadecano & 82 \\
\hline & - & & Eicosane & \\
\hline \multirow{8}{*}{ Madeira } & Tolueno & 93 & Dodecano & 82 \\
\hline & $\alpha$-Xileno & 98 & Tridecano & 80 \\
\hline & 1-etil-2-metil-benzeno & 95 & Tetradecano & 80 \\
\hline & 1,3,5- trimetil-benzeno & 99 & Pentadecano & 82 \\
\hline & 1h-indene, 1,2,3-dihidro-5-metil & 95 & Hexadecano & 83 \\
\hline & Dodecano & 81 & Heptadecano & 82 \\
\hline & Penta-metil-benzeno & 89 & Eicosane & 80 \\
\hline & 1h-indene, 2,3-dihidro-4,7-dimetil & 93 & - & \\
\hline \multirow{8}{*}{ Espuma } & Tolueno & 97 & Dodecano & 97 \\
\hline & $\alpha$-Xileno & 98 & Tridecano & 98 \\
\hline & 1-etil-2-metil-benzeno & 95 & Tetradecano & 95 \\
\hline & 1,3,5-trimetil-benzeno & 99 & Pentadecano & 99 \\
\hline & 1h-indene, 1,2,3-dihidro-5-metil & 98 & Hexadecano & 95 \\
\hline & Dodecano & 95 & Heptadecano & 93 \\
\hline & Penta-metil-benzeno & 90 & Eicosane & 89 \\
\hline & 1h-indene, 2,3-dihidro-4,7-dimetil & 89 & - & \\
\hline
\end{tabular}

incêndio. O detalhamento visual da simulação foi apresentado nas Figuras 1S-15S.

$\mathrm{Na}$ simulação, foi instalado um dispositivo para que a janela abrisse ao atingir a temperatura de $200{ }^{\circ} \mathrm{C}$, como se houvesse acontecido à quebra, temperatura essa encontrada na literatura nos trabalhos desenvolvidos por Babrauskas. ${ }^{42}$ No tempo de 60 segundos, iniciou-se a queima do colchão da cama superior pelos efeitos do incêndio iniciado no ar condicionado. No tempo de 244 segundos, houve a ignição da escrivaninha e no tempo de 330 segundos, ocorreu o incêndio no colchão da cama inferior.

A Figura 4 demonstra as imagens do ambiente real e do simulado ou virtual obtida a partir do software FDS. Considerando que o ambiente ventilado traz melhores condições de propagação para o incêndio, as conclusões extraídas nesse tipo de ambiente podem ser generalizadas para ambientes que apresentam condições mais desfavoráveis de ocorrer o desenvolvimento do incêndio.

Na Figura 4a observa-se um grande dano ocorrido na região externa à janela do quarto, onde por meio da simulação computacional apresentada na Figura 4c, é possível perceber a grande incidência das chamas na região externa na parede da janela, justificando o alto grau de destruição. Na Figura 4b observa-se um grande dano ocorrido no teto na saída do quarto onde se iniciou o incêndio, e por meio da simulação representada na Figura 4d, é possível notar uma grande incidência das chamas na região do teto. 
(a)

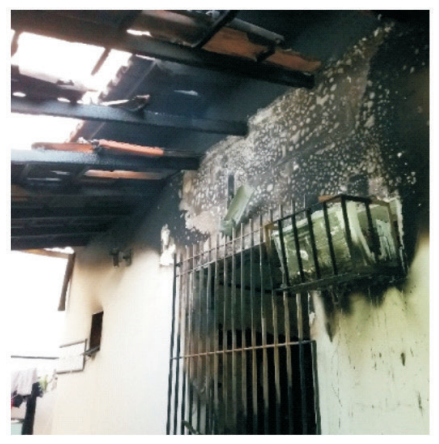

(b)

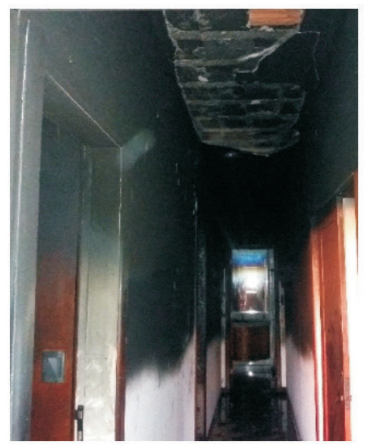

(d)

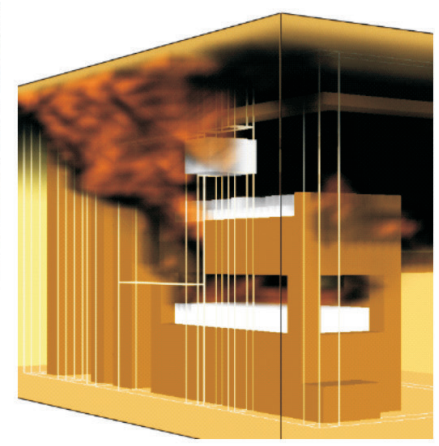

(d)

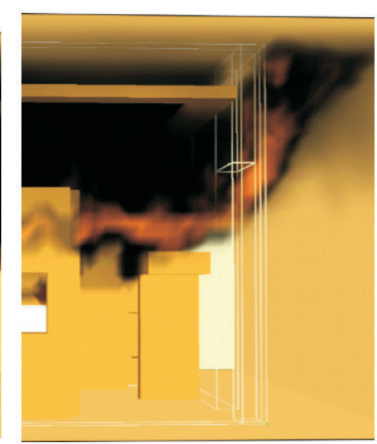

Figura 4. Comparativo com o cenário real do incêndio $(a)$ e (b) com o cenário virtual $(c)$ e (d)

A Figura 5 faz um comparativo entre a exposição sofrida na região do guarda-roupa e prateleiras (b) com os danos encontrados no cenário investigado (a) e (c). Apesar da temperatura que atingiu a parte externa do guarda-roupa chegar a $909{ }^{\circ} \mathrm{C}$ ser compatível com a carbonização completa da região, ${ }^{43}$ convém salientar a baixa condutividade térmica desse tipo de material que varia entre 0,055 a $0,28 \mathrm{~W} \mathrm{~m}^{-1}{ }^{\circ} \mathrm{C}^{-1},{ }^{15}$ dependendo do tipo de madeira, corroborando ainda mais para uma preservação da parte interior, o que não foram constatados na Figura 5, com um profundo grau de carbonização. Um tempo maior de exposição seria necessário contendo um alto nível de fluxo de calor, para que assim, conseguisse o consumo completo desse tipo de material. Isso também foi perceptível visualmente pela simulação, onde a primeira camada das células de madeira compreendida pela região mais externa não foi consumida com o incêndio.

Os incêndios envolvem reagentes, geralmente combustível e ar, não intimamente misturados em nível molecular antes da combustão. Normalmente, o combustível está no estado sólido ou líquido, portanto, a transferência de material através de um limite de fase (mudança de fase) também deve ocorrer. O combustível vaporizado deve combinar com o oxigênio do ar para formar uma mistura inflamável que, quando inflamada, forma a zona da chama. Na maioria dos problemas de incêndio, essa mistura de vapor de combustível e oxigênio ocorre principalmente por difusão e leva mais tempo em ordem de magnitude do que em uma reação química. Portanto, a difusão de espécies é o principal processo de controle durante esse comportamento de queima. ${ }^{38}$

A Figura 6 demonstra como ocorreu a variação da temperatura e do fluxo de calor ao longo do incêndio, em um termopar fixado na região da escrivaninha na entrada do quarto incendiado. Conforme os parâmetros estabelecidos por Braga $(2010)^{25}$ e por Figueroa e Moraes (2009), ${ }^{43}$ percebe-se que:

1) Os gases oriundos da pirólise da madeira da escrivaninha entraram em ignição em aproximadamente 260 segundos, tendo em vista o fluxo de calor nesse tempo encontrar-se em aproximadamente $13 \mathrm{~kW} \mathrm{~m}^{-2}$;

2) No tempo de aproximadamente 320 segundos observou-se a maior temperatura e fluxo de calor registrado nos termopares instalados sobre a escrivaninha. Atingindo um valor de $830^{\circ} \mathrm{C}$ de temperatura e $33,5 \mathrm{~kW} \mathrm{~m}^{-2}$ de fluxo de calor, no entanto, ambos se mantiveram por pouco tempo, tendo como consequência em virtude do fluxo de calor a ignição espontânea da madeira (sem a necessidade da presença do contato da chama). A temperatura é compatível com a carbonização da madeira, porém, isso só seria perceptível na camada exterior do móvel devido ao pouco tempo que se manteve a essa temperatura, não sendo suficiente para a queima completa;

3) Menos de 2 segundos após atingir o fluxo de calor máximo, o fluxo de calor caiu para a metade de seu valor e 8 segundos depois, para um terço do valor máximo, sendo esse valor suficiente para pirolisar o material combustível da escrivaninha.

A Figura 7 apresenta duas lâminas de monitoramento de temperatura que foram posicionadas, sendo uma com visão da região mais próxima ao beliche para parte interna do quarto (a) e outra com a visão da região da porta de acesso para o interior do quarto. A região de cor preta mostra a região do cômodo no qual a temperatura ainda (a)

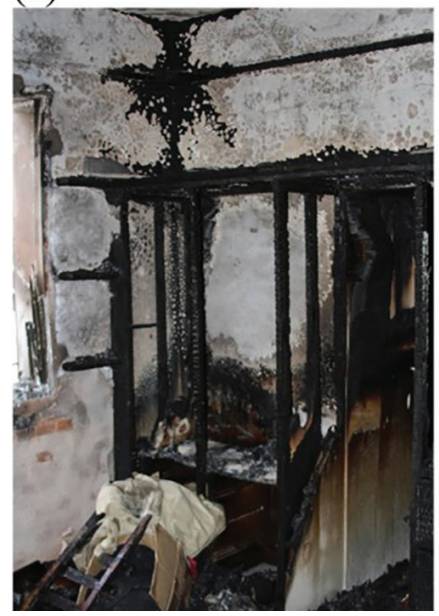

(b)

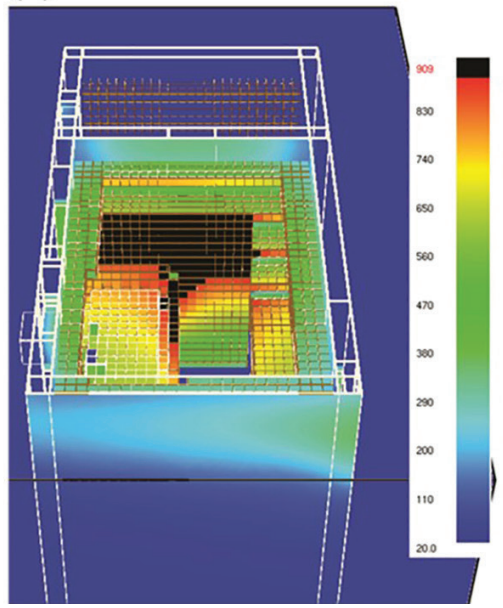

(c)

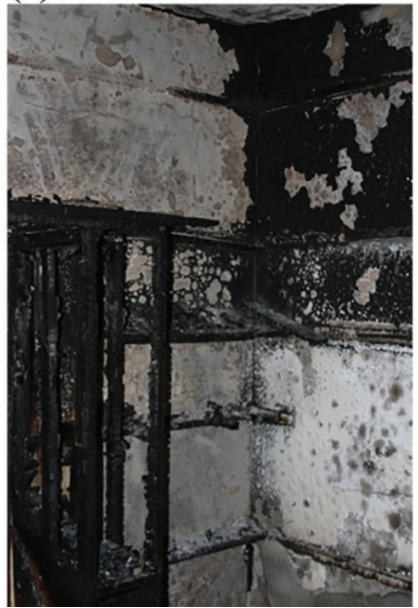

Figura 5. $(t=407 \mathrm{~s})$ - Momento no qual a maior região do guarda-roupa foi exposta a temperatura de $909^{\circ} \mathrm{C}$. (a) Danos ocorridos na região do guarda-roupas. (b) Simulação mostrando a região do guarda-roupas e prateleiras, demarcando o local (cor preta) com a maior temperatura atingida. (c) Danos ocorridos na região das prateleiras em virtude do incêndio 
Temperatura $\mathrm{x}$ Tempo

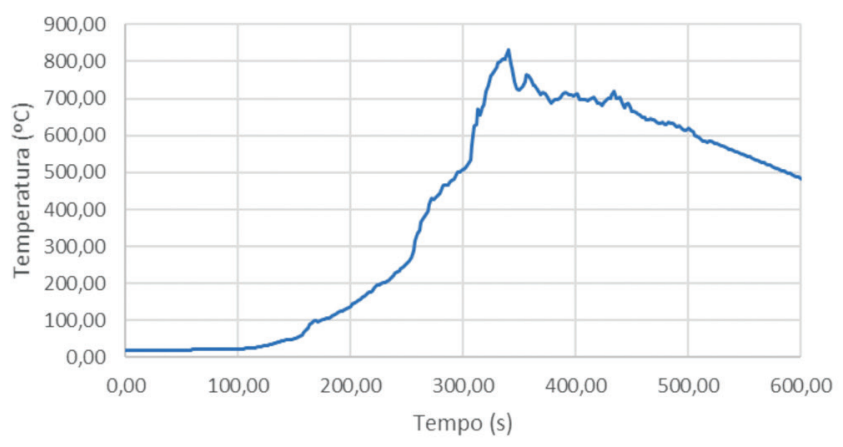

Fluxo de Calor x Tempo

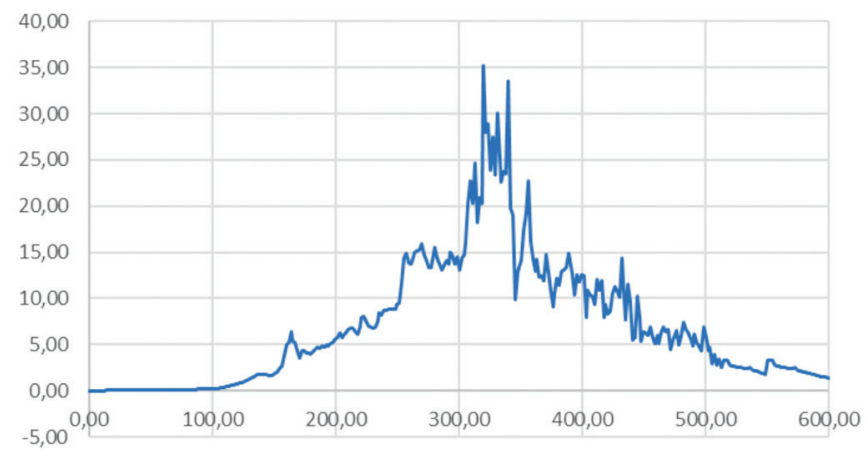

Figura 6. Variação da temperatura e do fluxo de calor do tampo da escrivaninha ao longo do tempo

proporciona condição de permanência de uma pessoa. Em relação às condições de vida no interior do quarto, com base na temperatura monitorada, observa-se que em um tempo de aproximadamente 6 minutos após o início do incêndio, ainda existe uma região no interior do cômodo onde a temperatura permitiria a presença de uma pessoa.

Não se podem desconsiderar os efeitos do fluxo de calor presentes em decorrência do incêndio que está em desenvolvimento, que apesar da temperatura na região demonstrar no tempo de 330 segundos é perfeitamente possível uma pessoa permanecer nessa região, o fluxo de calor poderia não permitir.

Levando-se isso em conta, nesse mesmo tempo registrado pelo termopar da escrivaninha, teve-se um fluxo de calor incompatível com a presença de uma pessoa no interior do ambiente. No entanto, no tempo de 230 segundos, é compatível em ter uma pessoa nessa região do quarto, devido à temperatura e o fluxo de calor serem compatíveis com os limites estabelecidos pelos trabalhos de Braga (2010). ${ }^{25} \mathrm{Na}$ Tabela 3 foi apresentado um resumo de todos os fenômenos observados no cenário de incêndio com o resultado da simulação caso o incêndio tivesse se desenvolvido de maneira natural, sem a utilização de um agente acelerante.

\section{Estudo de caso $n^{\circ} 2$}

Foram feitos alguns apontamentos baseados nos efeitos da temperatura, fluxo de calor e visibilidade decorrentes do incêndio que iniciou-se no colchão do quarto por meio da utilização de um dispositivo de acendimento do tipo isqueiro, que foi a hipótese testada para a ocorrência do incêndio. O detalhamento visual da simulação foram apresentados nas Figuras 16S-38S.

Na Figura 8 foi apresentada a temperatura monitorada no interior do quarto ao longo do desenvolvimento do incêndio. Com base nos estudos realizado por Braga (2010), ${ }^{25}$ identificou-se que a temperatura limite que um ser humano suportaria no interior do ambiente fica em torno de $50{ }^{\circ} \mathrm{C}$, portanto, foi utilizado esse valor para definir como condição inadequada para entrada e permanência de uma pessoa na região. Foram também apresentados os dados referentes à região interna do quarto onde se originou o incêndio, sendo os valores monitorados nas alturas de 0,$4 ; 0,8 ; 1,2 ; 1,6$ e 2,0 m, traçando-se dessa maneira um perfil das condições alcançadas com o desenvolvimento do incêndio. Com base na Figura 8a, observa-se que essa temperatura na altura de 2,0 $\mathrm{m}$ foi atingida no tempo de 77 segundos; na altura de 1,6 m no tempo de 103 segundos; na altura de 1,2 $\mathrm{m}$ no tempo de 112 segundos; na altura de $0,8 \mathrm{~m}$ no tempo de 146 segundos e na altura de $0,4 \mathrm{~m}$ no tempo de 202 segundos.

Na Figura 8b foi apresentada o fluxo de calor monitorado no interior do quarto. Com base nos estudos realizados por Braga (2010), ${ }^{25}$ identificou-se que o fluxo de calor limite que um ser humano suportaria no interior do ambiente fica em torno de $4,5 \mathrm{~kW} \mathrm{~m}^{-2}$, portanto, foi utilizado esse valor para definir como condição inadequada para
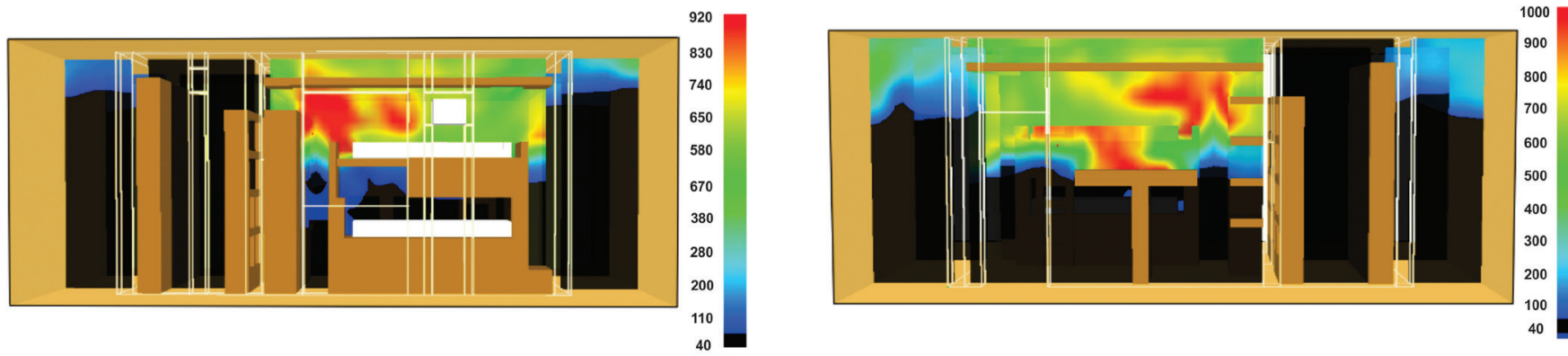

Figura 7. $(T=330 \mathrm{~s})$-Vista Posterior e Frontal - Temperatura de $40^{\circ} \mathrm{C}$ na região da cama de inferior e abaixo da escrivaninha (região preta). (a) Corte feito da região próxima a casa. (b) Corte realizado na entrada do quarto

Tabela 3. Resumo dos fenômenos verificados com a simulação com o FDS e constatados no local do incêndio

\begin{tabular}{ccc}
\hline Fenômeno & No local & Na simulação (FDS) \\
\hline Destruição da Escrivaninha & Total & Parcial \\
Danos no Guarda Roupa & Total & Parcial \\
Queima do Colchão & Total & Causaria queimadura de $2^{\circ}$ grau \\
Condição de Entrada no Ambiente (Sem visibilidade) & Adentrou sem causar queimaduras & Condições de sobreviver no colchão inferior até \\
Condição de Vida do Interior do ambiente & Vítimas Fatais que não se movimentaram & 4 minutos \\
\hline
\end{tabular}


(a)

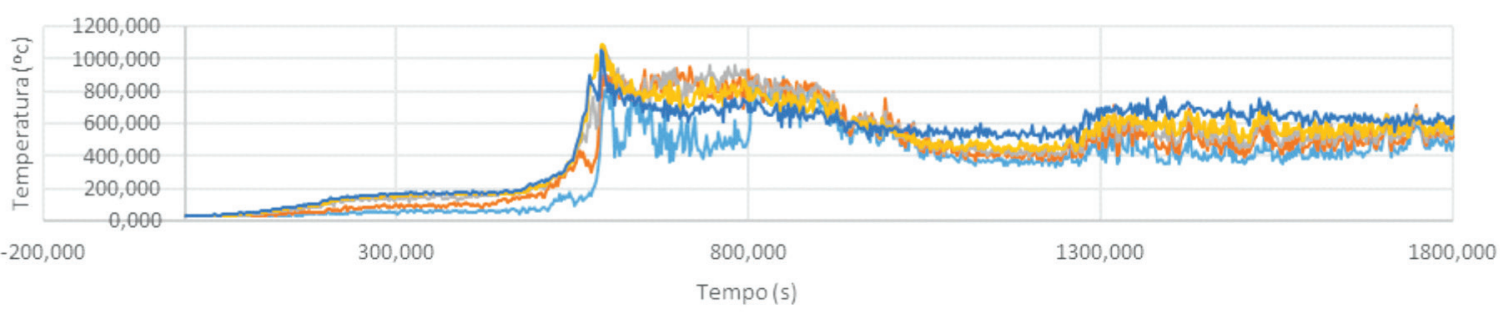

(b)

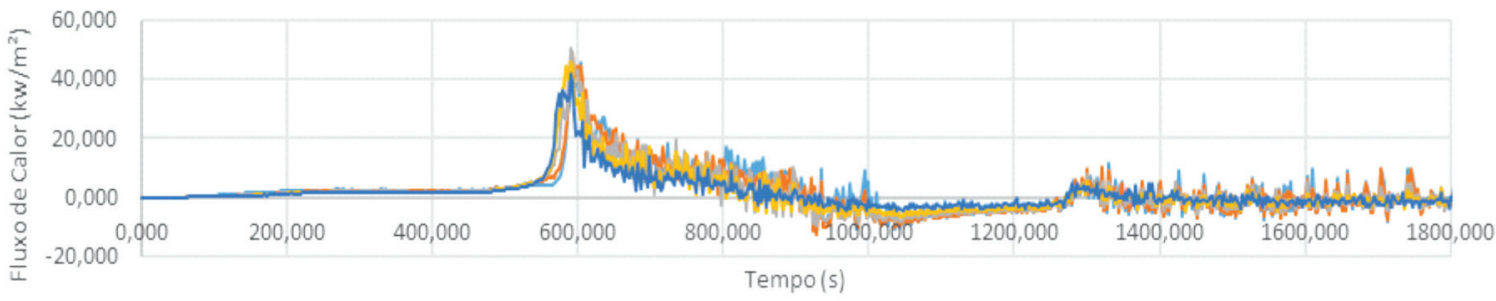

(c)

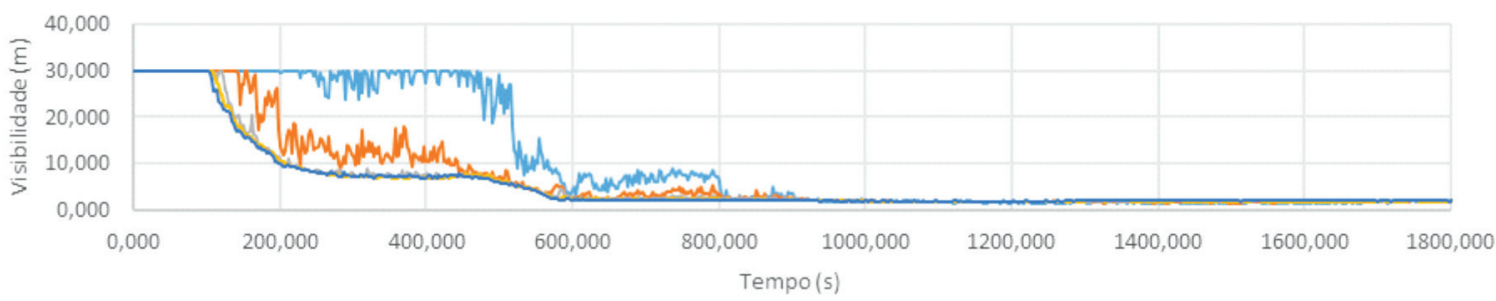

Figura 8. Variação dos parâmetros monitorados no interior do quarto

entrada e permanência de uma pessoa no interior do recinto. Observase que esse fluxo de calor na altura de 2,0 $\mathrm{m}$ foi atingida no tempo de 540 segundos; na altura de 1,6 m no tempo de 532 segundos; na altura de $1,2 \mathrm{~m}$ no tempo de 530 segundos; na altura de $0,8 \mathrm{~m}$ no tempo de 532 segundos e na altura de $0,4 \mathrm{~m}$ no tempo de 568 segundos.

$\mathrm{Na}$ Figura 8c foi apresentada a visibilidade monitorada no interior do quarto. Os valores foram normalizados para uma distância de $30 \mathrm{~m}$, entendendo-se como a visibilidade máxima que uma pessoa consegue atingir. À medida que o incêndio se propaga, em decorrência do acúmulo da fumaça no interior da edificação, esse parâmetro foi alterando, aproximando-se do valor $0 \mathrm{~m}$ que corresponde a nenhuma visibilidade do ambiente monitorado. Observa-se que a visibilidade atingiu um valor correspondente a $50 \%$ da sua capacidade na altura de 2,0 $\mathrm{m}$ no tempo de 160 segundos; na altura de 1,6 $\mathrm{m}$ no tempo de 163 segundos; na altura de 1,2 m no tempo de 168 segundos; na altura de $0,8 \mathrm{~m}$ no tempo de 208 segundos e na altura de $0,4 \mathrm{~m}$ no tempo de 520 segundos. A visibilidade de $10 \%$ foi atingida, na altura de 2,0 m, no tempo de 564 segundos; na altura de 1,6 m no tempo de 566 segundos; na altura de 1,2 m no tempo de 571 segundos; na altura de $0,8 \mathrm{~m}$ no tempo de 590 segundos e na altura de $0,4 \mathrm{~m}$ no tempo de 804 segundos.

Na Figura 9 foram apresentados os dados referentes a região externa do quarto, sendo posicionados os dispositivos para medição na região da entrada da edificação, onde os valores monitorados nas alturas de $0,4 \mathrm{~m} ; 0,8 \mathrm{~m} ; 1,2 \mathrm{~m} ; 1,6 \mathrm{~m}$ e 2,0 m, possibilitaram que fosse traçado um perfil das condições alcançadas com o desenvolvimento do incêndio.

Na Figura 9a foi apresentada a temperatura monitorada na entrada da edificação. Observa-se que a temperatura limite suportada pelo ser humano na altura de 2,0 m foi atingida no tempo de 130 segundos; na altura de 1,6 m no tempo de 149 segundos; na altura de $1,2 \mathrm{~m}$ no tempo de 196 segundos; na altura de 0,8 m no tempo de 523 segundos e na altura de 0,4 m no tempo de 573 segundos.

Na Figura 9b foi apresentada o fluxo de calor monitorada na entrada da edificação. Observa-se que o fluxo de calor limite suportado pelo ser humano na altura de 2,0 $\mathrm{m}$ foi atingida no tempo de 573 segundos; na altura de 1,6 m no tempo de 578 segundos; na altura de $1,2 \mathrm{~m}$ no tempo de 581 segundos; na altura de $0,8 \mathrm{~m}$ no tempo de 590 segundos e na altura de 0,4 m no tempo de 605 segundos.

$\mathrm{Na}$ Figura 9c foi apresentada a visibilidade monitorada na entrada da edificação. Observa-se que a visibilidade atingiu um valor correspondente a $50 \%$ da sua capacidade na altura de $2,0 \mathrm{~m}$ no tempo de 185 segundos; na altura de $1,6 \mathrm{~m}$ no tempo de 201 segundos; na altura de 1,2 $\mathrm{m}$ no tempo de 226 segundos; na altura de $0,8 \mathrm{~m}$ no tempo de 523 segundos e na altura de $0,4 \mathrm{~m}$ no tempo de 561 segundos. A visibilidade $10 \%$ foi atingida, na altura de 2,0 m, no tempo de 571 segundos; na altura de 1,6 m no tempo de 578 segundos; na altura de 1,2 m no tempo de 578 segundos; na altura de $0,8 \mathrm{~m}$ no tempo de 585 segundos e na altura de $0,4 \mathrm{~m}$ no tempo de 619 segundos.

Em relação aos danos observados, foi monitorada a degradação ocorrida no colchão no qual foi iniciado o incêndio, na porta de acesso ao banheiro e no sofá existente na região próxima à entrada da edificação, com base na observação visual da simulação realizada. Em relação aos danos do colchão no qual se iniciou o incêndio, observa-se que em um tempo de 994 segundos após o início da simulação, ocorreu sua total degradação. Em relação ao sofá, observa-as que sua degradação foi iniciada em um tempo de aproximadamente 600 segundos, acentuando-se em um tempo de 750 segundos de simulação. Em relação a porta de entrada do banheiro, observa-se que sua queima iniciou no tempo de aproximadamente 1200 segundos, que sua região onde iniciou a sua degradação corresponde a região superior, ao lado direito de dentro do quarto para a região do banheiro, conforme Figura 10.

Para subsidiar essa análise da degradação da porta do banheiro, foram monitorados a temperatura, fluxo de calor e visibilidade do interior do banheiro a uma altura de $0,4 \mathrm{~m}$. Os valores obtidos foram plotados nas Figuras 11 (a, b e c) e analisados utilizando as premissas anteriormente empregadas. Conforme observado, no tempo de 1270 segundos, foi observado um valor de temperatura de $50{ }^{\circ} \mathrm{C} \mathrm{e}$ fluxo de calor de $4,5 \mathrm{~kW} \mathrm{~m}^{-2}$, que impossibilita a permanência de uma pessoa no ambiente, no tempo de 1277 segundos, visibilidade próximo ao valor de 0 no interior do banheiro. 
(a)

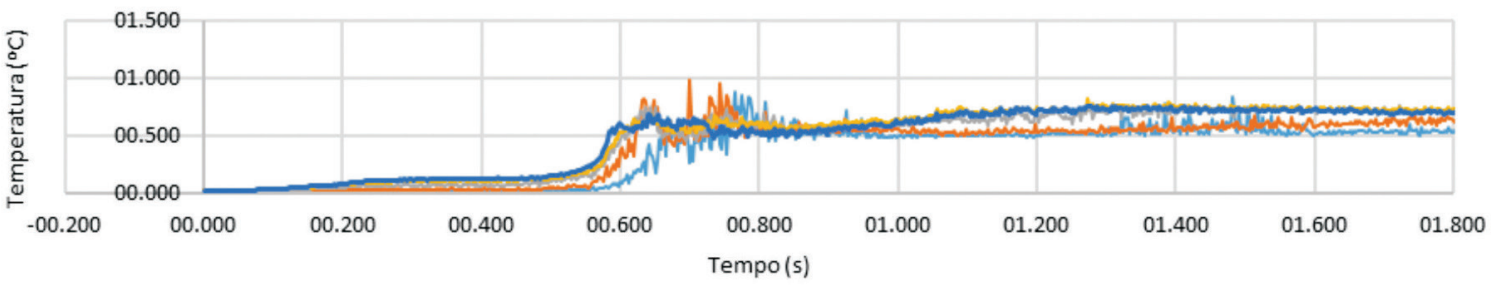

(b)

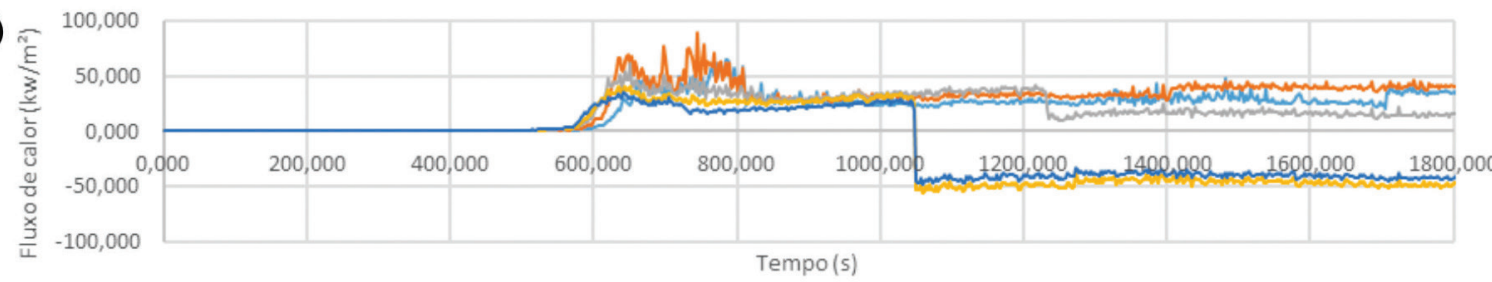

(c)

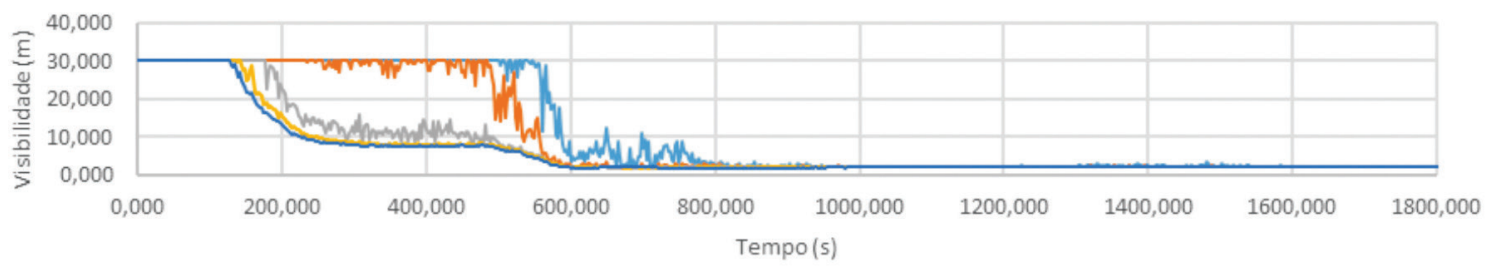

Figura 9. Variação dos parâmetros monitorados na entrada da residência
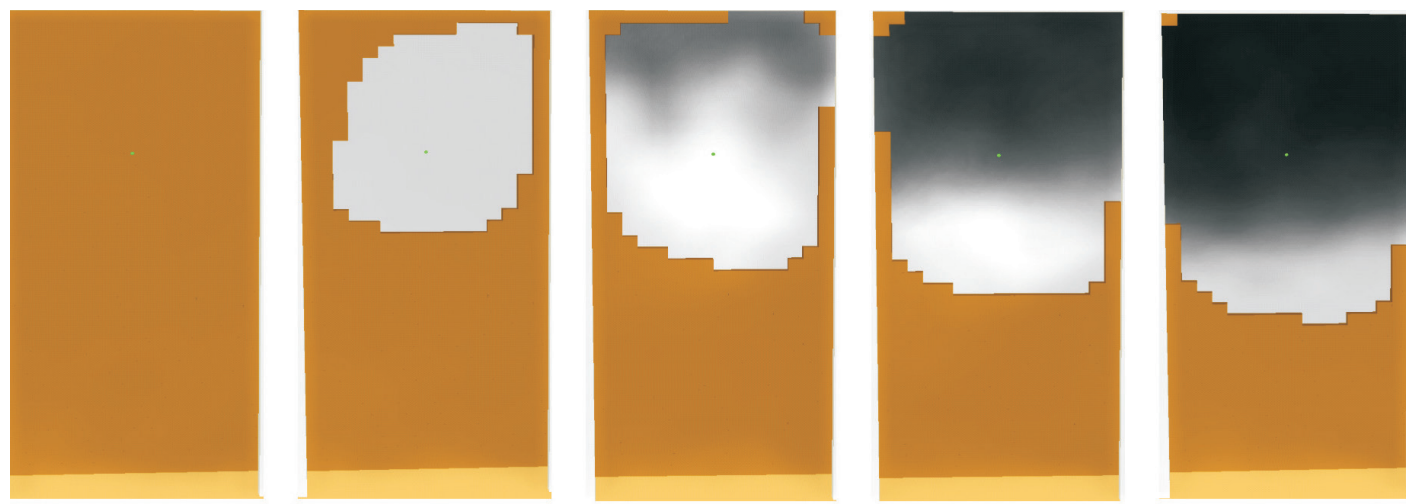

Figura 10. Sentido de degradação da porta de entrada do banheiro

(a)

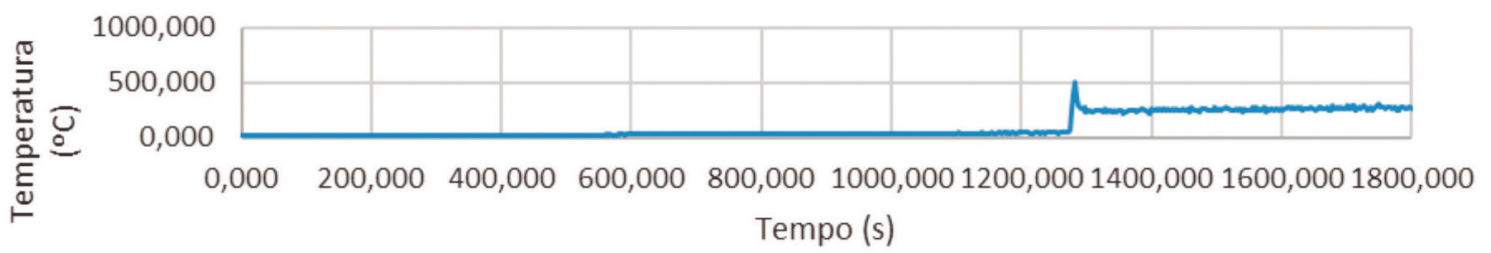

(b)

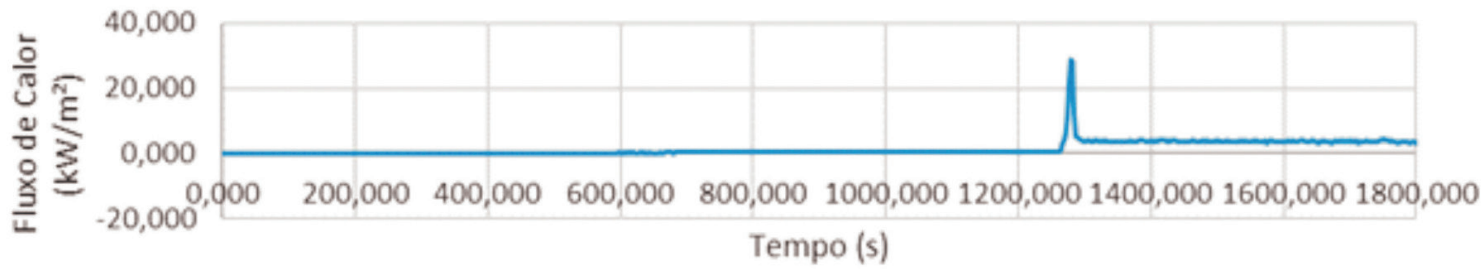

(c)

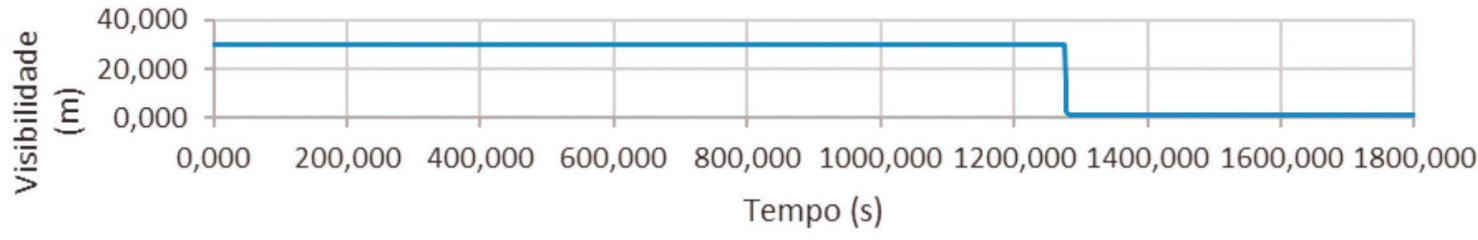

Figura 11. Variação dos parâmetros monitorados no interior do banheiro 
Baixa intensidade $(\mathrm{t}=120 \mathrm{~s})$

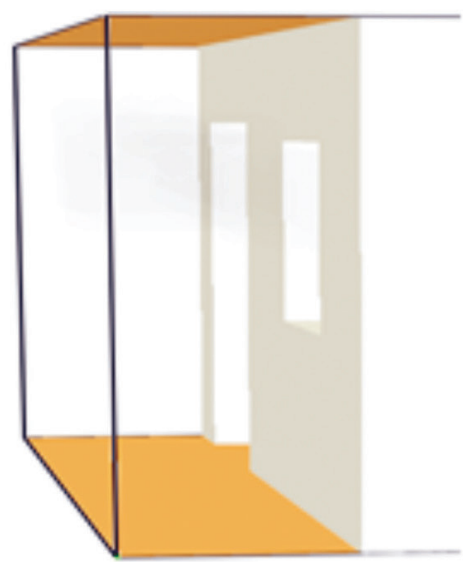

Média intensidade $(\mathrm{t}=300 \mathrm{~s})$

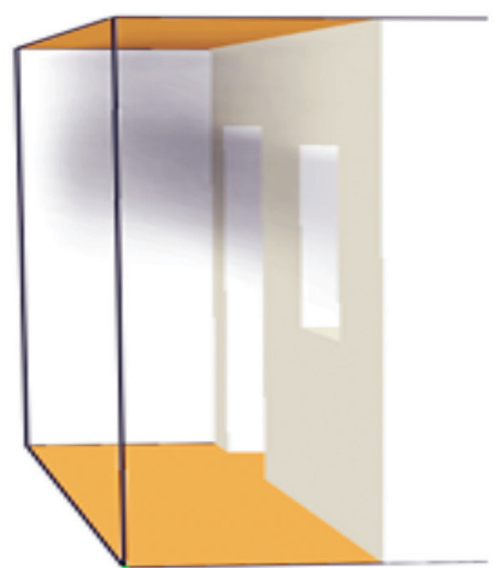

Alta intensidade $(\mathrm{t}=568 \mathrm{~s})$

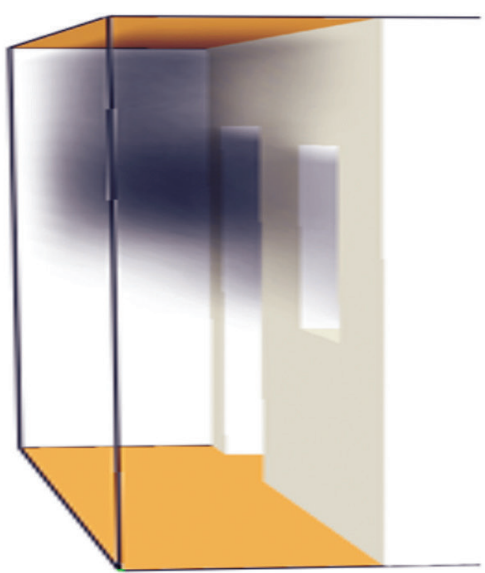

Figura 12. Análise visual da fumaça saindo da edificação que ocorreu o incêndio

A partir da Figura 11, é possível perceber uma alteração abrupta nos valores analisados em um tempo de aproximadamente 1280 segundos, resultante da degradação da porta de entrada do ambiente, o que possibilitou o desenvolvimento do incêndio nessa região na qual se encontrava isolado e com pressão absoluta inferior à do quarto o qual se iniciou o incêndio.

Em relação à visualização da fumaça saindo pela porta, foi realizada uma análise visual da simulação produzida, sendo representada na Figura 12 com os tempos referente a percepção visual que uma pessoa teria visualizando o incêndio pelo lado de fora da edificação.

Observa-se que em um tempo de 120 s, já é possível visualizar a fumaça saindo pela porta de entrada da edificação, tempo no qual uma pessoa ainda seria capaz de adentrar a todo o ambiente, conforme os parâmetros temperatura, fluxo de calor e visibilidade analisados. No tempo de $568 \mathrm{~s}$, visualiza-se uma fumaça de maior intensidade, que coincide com o tempo limite para uma pessoa possa adentrar até na porta do quarto da edificação.

\section{CONCLUSÃO}

Os resultados obtidos demonstraram que é possível identificar a presença de gasolina e diesel em diferentes tipos de substratos queimados na presença desses acelerantes e que a utilização da fibra de carbono para a extração e preparação da amostra se mostrou ser um método eficiente. Dessa forma, durante os trabalhos investigativos, pode-se perceber que uma amostra de um material poroso, como uma espuma de colchão, é mais interessante de ser coletada, tendo em vista a melhor resposta na identificação do acelerante de interesse.

Em relação às simulações realizadas, no estudo de caso 1 , a destruição completa da escrivaninha e a queima completa do colchão da cama superior não foi observada nos 10 minutos de simulação. Em relação as prateleiras do guarda-roupa presentes no extremo direito do móvel, evidenciou-se que ficaram parcialmente protegidas, mantendo-se uma integridade superior ao restante do guarda-roupa. A destruição generalizada no quarto só seria possível, dentro dos parâmetros estabelecidos, em um tempo superior a 10 minutos. Dessa forma, com um acentuado grau de destruição que ocorreu no cenário de incêndio real em um tempo inferior a 10 minutos, leva-se a uma possível suspeita na utilização de agente acelerante para o rápido desenvolvimento do incêndio.

No estudo de caso 2, os resultados obtidos demonstraram que o limite tolerável para acesso e permanência de uma pessoa agachada a uma altura de $40 \mathrm{~cm}$ do solo, se deu até o tempo de aproximadamente 9 minutos e 30 segundos após o início da simulação. No interior do quarto, o limite tolerável para acesso e permanência de uma pessoa agachada a uma altura de $40 \mathrm{~cm}$ do solo, se deu até o tempo de aproximadamente 3 minutos e 30 segundos após o início da simulação. No banheiro do quarto, após um tempo de aproximadamente 21 minutos, o ambiente tornou-se incompatível para a permanência de uma pessoa em seu interior. Em relação aos danos observados, conclui-se que o consumo total do colchão, que foi o foco inicial do incêndio, se deu em um tempo de 16 minutos e 30 segundos, a degradação do sofá em um tempo de 30 minutos. A porta do banheiro foi degradada pela metade em um tempo de aproximadamente 21 minutos após o início do incêndio, com uma direção diagonal e um sentido esquerda descendente.

Desse modo, a análise de acelerante e a simulação usando o FDS demonstraram ser importantes ferramentas para auxiliar o perito na investigação do incêndio para o descarte de hipóteses, auxiliando a entender quais substâncias estão presentes no cenário e as condições que foram atingidas no decorrer do incêndio, no entanto, deve ser encarada como uma ferramenta suplementar, visto que para a correta aproximação da simulação com a realidade, é necessário um conjunto de variáveis que nem sempre estarão disponíveis no cenário de incêndio.

\section{MATERIAL SUPLEMENTAR}

Parametrização dos materiais da simulação, figuras demonstrando as etapas dos incêndios simulados, cromatogramas e espectros de massas das análises estão disponíveis em http://quimicanova.sbq. org.br, na forma de arquivo PDF, com acesso livre.

\section{AGRADECIMENTOS}

Os autores agradecem a CAPES (23038.007083/2014-40), FAPES (EDITAL CNPq/FAPES No 23/2018 - Programa de Apoio a Núcleos Emergentes - PRONEM), e a CNPq (422555/2018-5, and 305359/2017-7) pelo suporte financeiro. Os autores também gostariam de agradecer ao Núcleo de Competências em Química do Petróleo e ao LabPetro pelo uso de suas instalações e ao Corpo de Bombeiros Militar do Estado do Espírito Santo pelas informações fornecidas para o desenvolvimento da pesquisa.

\section{REFERÊNCIAS}

1. https://sesp.es.gov.br/estat\%C3\%ADsticas-criminais-2, acessada em Setembro 2019. 
2. Ji, J.; Guo, F.; Gao, Z.; Zhu, J.; Sun, J.; Appl. Therm. Eng. 2017, 118, 663.

3. Heidarinejad, G.; Mapar, M.; Pasdarshahri, H.; Tunnelling and Underground Space Technology 2016, 59, 91.

4. Fan, C.; Zhang, L.; Jiao, S.; Yang, Z.; Li, M.; Liu, X.; Tunnelling and Underground Space Technology 2018, 82, 99.

5. Rajendram, A.; Khan, F.; Garaniya, V.; Fire Saf. J. 2015, 71, 79.

6. Gong, X.; Agrawal, A. K.; Journal of Bridge Engineering 2016, $21,82$.

7. Ding, Y.; Yang, L.; Weng, F.; Fu, Z.; Rao, P.; Simulation Modelling Practice and Theory 2015, 53, 60.

8. Falatová, B.; Ferreiro-González, M.; Ka iková, D.; Galla, S.; Palma, M.; Barroso, C. G.; Acta Fac. Xylol. Zvolen 2019, 61, 111.

9. Ferreiro-González, M.; Ayuso, J.; Álvarez, J. A.; Palma, M.; Barroso, C. G.; Talanta 2015, 142, 150.

10. Ferreiro-González, M.; Barbero, G. F.; Palma, M.; Ayuso, J.; Álvarez, J. A.; Barroso, C. G.; Sensors 2016, 16, 695.

11. Montani, I.; Comment, S.; Delémont, O.; Forensic Sci. Int. 2010, 194, 115 .

12. National Fire Protection Association; NFPA 921: Guide for Fire \& Explosion Investigations; Technical Committee on Fire Investigations, 2013.

13. Salgueiro, P.; Borges, C.; da Silva, R. J. N. B.; J. Chromatogr. A 2012, 1257, 189.

14. De Haan, J. D.; Icove, D. J.; Kirk's Fire Investigation: Pearson New International Edition; Pearson Higher Education: London, England, 2013.

15. Cote, A. E.; Fire protection handbook; National Fire Protection Association, Quincy, MA, USA, 2008.

16. Heath, K.; Kobus, H.; Byard, R. W.; Journal of Forensic and Legal Medicine 2011, 18, 49.

17. Grob, R. L.; Barry, E. F.; Modern Practice of Gas Chromatography; John Wiley \& Sons: Hoboken, NJ, USA, 2004.

18. Martín-Alberca, C.; Ortega-Ojeda, F. E.; Garcia-Ruiz, C.; Anal. Chim. Acta 2016, 928, 1.

19. ASTM E1412-00: Standard Practice for Separation of Ignitable Liquid Residues from Fire Debris Samples by Passive Headspace Concentration with Activated Charcoal; ASTM International, West Conshohocken, PA, 2000.

20. Salgueiro, P. A. S.; Borges, C. M. F.; da Silva, R.; J. Chromatogr. A 2012, 1257, 189.

21. Prather, K. R.; Mcguffin, V. L.; Smith, R. W.; Forensic Sci. Int. 2012, $222,242$.

22. Lopatka, M.; Sigman, M. E.; Sjerps, M. J.; Williams, M. R.; VivóTruyols, G.; Forensic Sci. Int. 2015, 252, 177.

23. Sandercock, P. M. L.; J. - Can. Soc. Forensic Sci. 2016, 49, 176.

24. McGrattan, K.; Hostikka, S.; McDermott, R.; Floyd, J.; Weinschenk, C.; Overholt, K.; Fire Dynamics Simulator (version 6.5.3): User's guide; National Institute of Standards and Technology: Gaithersburg, 2017.
25. Braga, G. C. B.; XI Seminário Nacional de Bombeiro/SENABOM, Blumenau, Santa Catarina, Brasil, 2010.

26. http://www.periodicos.capes.gov.br, acessada em Setembro 2019.

27. Yong-Hak, J.; Web of Science; Thomson Reuters, 2013.

28. Mcgrattan, K. B.; Bouldin, C.; Forney, G. P.; Computer simulation of the fires in the World Trade Center Towers; US Department of Commerce, Technology Administration, National Institute of Standards and Technology: Washington, Gaithersburg, 2005.

29. Grosshandler, W.; Bryner, N.; Madrzykowski, D.; Kuntz, K.; Report of the technical investigation of The Station Nightclub fire, vol. 1; Escritório de Impressão do Governo dos EUA: Washington, DC, 2005.

30. Madrzykowski, D.; Vettori, R. L.; Simulation of the dynamics of the fire at 3146 Cherry Road NE, Washington DC, May 30, 1999; US Department of Commerce, Technology Administration, National Institute of Standards and Technology: Washington, Gaithersburg, 2000.

31. Madrzykowski, D.; Forney, G. P.; Walton, W. D.; Simulation of the dynamics of a fire in a two-story duplex-Iowa, December 22, 1999; US Department of Commerce, Technology Administration, National Institute of Standards and Technology: Washington, Gaithersburg, 2002.

32. Bryner, N. P.; Kerber, S.; Simulation of the Dynamics of a Fire in the Basement of a Hardware Store-New York, June 17, 2001; National Institute of Standards and Technology, Building and Fire Research Laboratory, Gaithersburg, 2004.

33. Barowy, A.; Madrzykowski, D.; Simulation of the Dynamics of a Wind-driven Fire in a Ranch-style House, Texas; National Institute of Standards and Technology, Fire Research Division Engineering Laboratory, Gaithersburg, 2012.

34. Speight, J. G.; The chemistry and technology of petroleum; CRC Press: Boca Raton, FL, USA, 2014.

35. ASTM E1387-01: Standard Test Method for Ignitable Liquid Residues in Extracts from Fire Debris Samples by Gas Chromatography (Withdrawn 2010); ASTM International, West Conshohocken, PA, 2001.

36. https://sistemasinter.cetesb.sp.gov.br/produtos/ficha_completa1. asp?consulta=\%C3\%93LEO\%20DIESEL, acessada em Agosto 2019.

37. https://sistemasinter.cetesb.sp.gov.br/produtos/ficha_completa1. asp?consulta=GASOLINA:\%20NATURAL, acessada em Agosto 2019.

38. Hurley, M. J.; Gottuk, D. T.; Hall Jr., J. R.; Harada, K.; Kuligowski, E. D.; Puchovsky, M.; Wieczorek, C. J.; SFPE handbook of fire protection engineering; Springer: New York, USA, 2015.

39. Norma técnica 04/2009: Carga de incêndio nas edificações e áreas de risco; Corpo de Bombeiros Militar do Estado do Espírito Santo: Vitória, 2019.

40. Stauffer, E.; Byron, D.; Forensic Sci. Int. 2007, 52, 371.

41. Visotin, A.; Lennard, C.; Aust. J. Forensic Sci. 2016, 48, 203.

42. Babrauskas, V.; Glass breakage in fires; Fire Science and Technology, Inc.: Issaquah, WA, 2011.

43. Figueroa, M. J. M.; de Moraes, P. D.; Ambiente Construído 2009, 9, 157. 